\title{
Biological Matrix for 2.5D Renal Model in vitro
}

\author{
Alodia Lacueva Aparicio ${ }^{12}$, Luis Fernández Ledesma ${ }^{1}$, Ignacio Giménez López ${ }^{2}$ \\ ${ }^{1}$ Tissue MicroEnvironment (TME Lab) \\ ${ }^{2}$ Renal and Cardiovascular Physiopathology (FISIOPREN) \\ Instituto de Investigación en Ingeniería de Aragón (I3A) \\ Universidad de Zaragoza, Mariano Esquillor s/n, 50018, Zaragoza, Spain.
}

Tel. +34-976762707, e-mail: alodia@unizar.es

\section{Summary}

The extracellular matrix provides mechanical support to renal cells and enhance tridimensional disposition in cell culture (1). For that reason, biological matrices are widely used in renal models in vitro. Here we present a user-friendly 2.5D renal model that can be used for nephrotoxic assays.

\section{Results}

\subsection{D renal cell culture}

Renal models in vitro have become more sofisticated and complex over the years. Traditional cell culture is being replaced by tridimensional cell culture, which mimics renal structure and function. Some of the protocols set for recreating tubule-like structures are time consuming and expensive (2). We have developed a protocol in order to reproduce proximal tubule structure using a stablished cell line, RPTEC/TERT1. Cells were mixed with 5\% Matrigel and seeded on top of a biological matrix made of collagen I and Matrigel. After $24 \mathrm{~h}$ in cell culture, proximal tubule cells in traditional cell culture on a plastic surface reproduced a monolayer as expected (Fig. 1A). In contrast, RPTEC/TERT1 formed tubule-like structures on the matrix surface (Fig. 1B). Afterwards gen expression of four transporters present in proximal tubule cells was analized by qPCR. OAT1 and OCT1 transporters were present in both control (monolayer) and hydrogel (tubule-like structures). OCT1 is slightly overexpressed in the 2.5D model but OAT3 and OCT2 transporters are missing in both conditions (Fig.1C).

\section{Tubule-like structures mimic proximal tubule in vivo}

RPTEC/TERT1 in 2.5D model showed some characteristics found in proximal tubule in vivo. The tight junction known as zonula occludens (ZO-1), which is present in renal tissue, is expressed also in tubule-like structures (Fig.2 A, D), proving that RPTEC/TERT1 are in contact as observed in renal epithelial cells within the kidney. Moreover, these cells are polarized towards a central lumen. Presence of primary cilia within the lumen and the apical disposition of actin showed polarization of these renal tubules in vitro (Fig.2B, E)(3).

\section{Nephrotoxic assays}

In order to validate our model for drug testing, two well known nephrotoxic compounds were used. After one week in cell culture, RPTEC/TERT1 were exposed to different concentrations of daunorubicin (Fig. 3A) and cisplatin (CDDP) (Fig. 3B). 48h after exposure, cells in monolayer (ED50 $=77.23$ ) seemed to be more sensitive to CDDP than tubule-like structures (ED50=98.67). On the other hand, when cells were exposed to daunorubicin, sensitivity was higher in tubules than in monolayer (ED50 $=42.91$ vs 87.62).

\section{Conclusions}

Novel kidney models in vitro have arisen as the best alternative to reproduce renal tissue. Biological and syntethic scaffolds are used worldwide in these models. We have developed a protocol which recapitulates proximal tubule structure using an established commercial cell line and a biological matrix in order to get robust results when compared with traditional cell culture. RPTEC/TERT1 express some of the most characteristic markers in proximal tubule cells as OAT1, OCT1, ZO-1 and primary cilia. It has been validated also for drug testing. For these reasons, this model could be a useful tool for nephrotoxic assays not only to replace traditional cell culture in 2D but also to reduce animal testing for new drugs discovery.

Revista “Jornada de Jóvenes Investigadores del I3A”, vol. 8 (Actas de la IX Jornada de Jóvenes Investigadores del I3A -11 de diciembre de 2020). ISSN 2341-4790. 


\section{FIGURES}
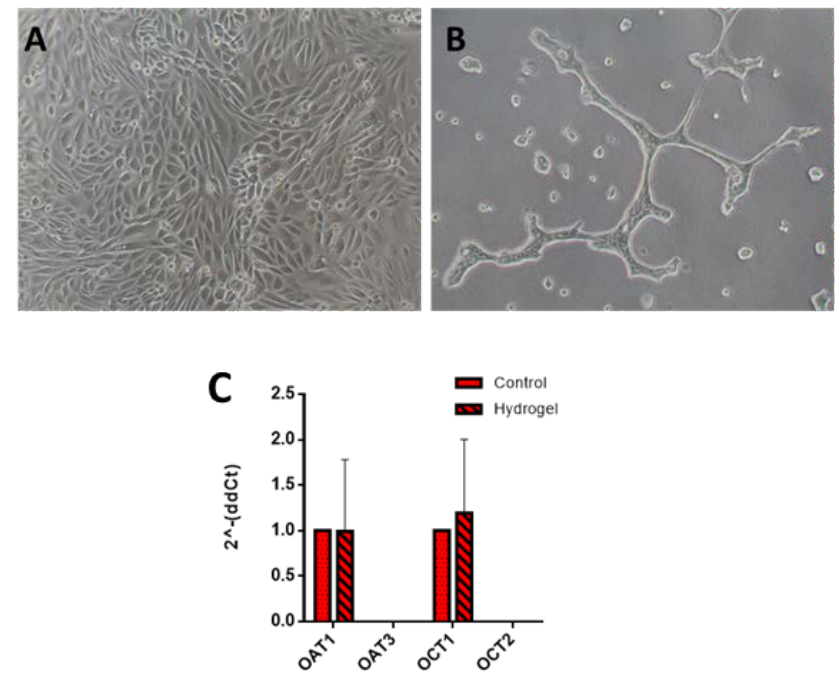

Figure 1. RPTEC tubule-like structures formation depends on the presence of different components. Cells were seeded either on a plastic surface (A) or on top of Collagen I + Matrigel (90:10) hydrogel (B). RPTEC mixed with 5\% Matrigel showed tubulogenesis (B) and cells in traditional cell culture without $5 \%$ Matrigel formed a monolayer on top of the plastic surface.
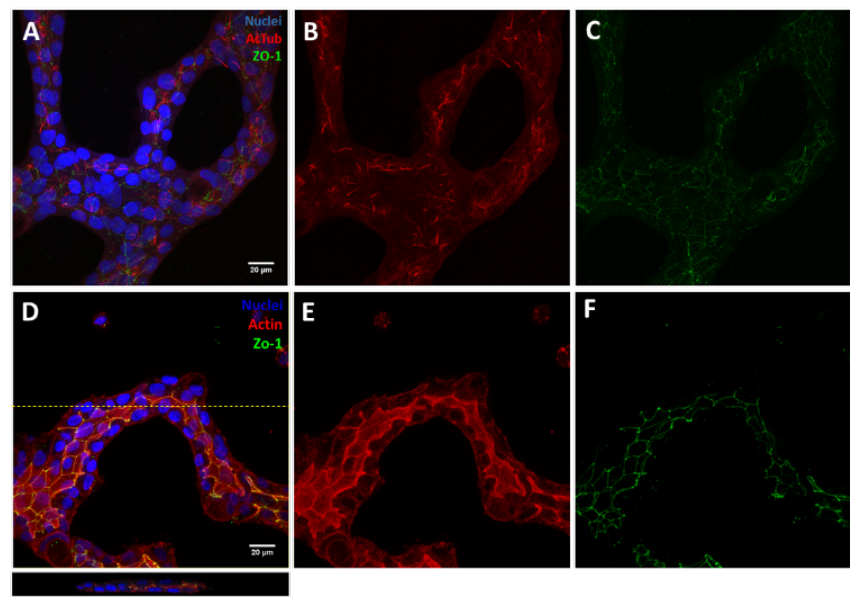

Figure 2. RPTEC/TERT 1 seeded on top of the hydrogel showed a tubule-like structure. Primary cilia are directed towards the lumen $(B)$ and actin defines the inner part of the tubule-like structure (E). ZO-1 is a specific marker of proximal tubule cells and it is expressed in RPTEC/TERT1 (C and F).
A

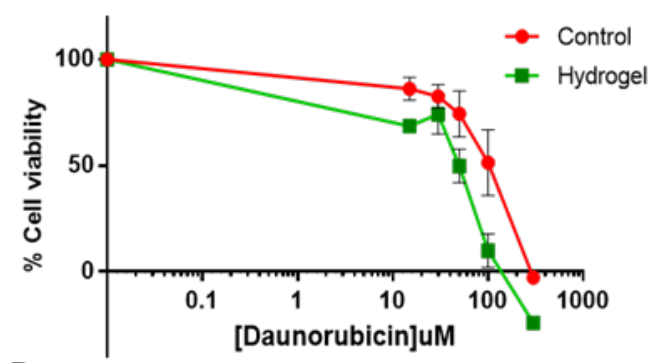

B

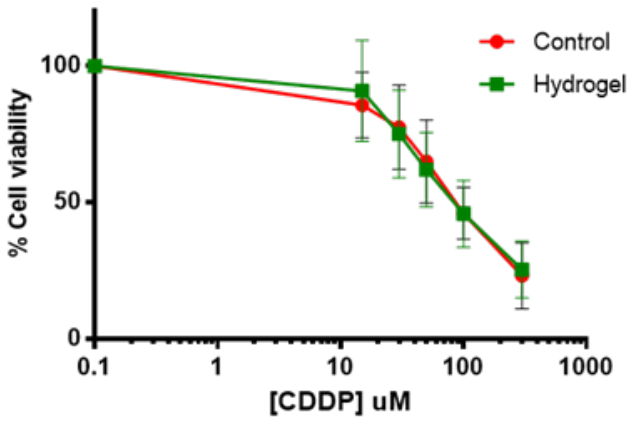

Figure 3. RPTEC/TERT1 tubule-like structures as a model for nephrotoxic assays. After $\mathbf{7}$ days of cell culture, renal cells were treated with two different nephrotoxic drugs, cisplatin and daunorubicin. Graphic shows \% of cell viability after cells were exposed to the different concentrations of CDDP or daunorubicin. IC50 CDDP: control 77.23; hydrogel 98.67. IC50 Daunorubicin: control 87.62; hydrogel 42.91.

\section{REFERENCES}

1. LOGANATHAN, Rajprasad, LITTLE, Charles D and RONGISH, Brenda J. Extracellular matrix dynamics in tubulogenesis. Cellular Signalling. 2020. Vol. 72, no. April, p. 109619.

SECKER, Philipp. RPTEC/TERT1 cells form highly differentiated tubules when cultured in a 3D matrix. Altex. 2017. P. 1-12.

3. ZEGERS, Mirjam M P, O’BRIEN, Lucy E, YU, Wei, DATTA, Anirban and MOSTOV, Keith E. Epithelial polarity and tubulogenesis in vitro. Trends in cell biology. April 2003. Vol. 13, no. 4, p. 169-76.

4. DESROCHERS, Teresa M., SUTER, Laura, ROTH, Adrian and KAPLAN, David L. Bioengineered 3D Human Kidney Tissue, a Platform for the Determination of Nephrotoxicity. PLOS ONE. 2013. Vol. 8, no. 3 . 